\title{
Isolation of three dormancy QTLs as Mendelian factors in rice
}

\author{
X-Y Gu ${ }^{1}$, SF Kianian ${ }^{1}$ and ME Foley ${ }^{2}$ \\ ${ }^{1}$ Department of Plant Sciences, North Dakota State University, Fargo, ND 58105, USA; ${ }^{2}$ Biosciences Research Laboratory \\ USDA - Agricultural Research Service, Fargo, ND 58105-5674, USA
}

\begin{abstract}
Seed dormancy is a key adaptive trait under polygenic control in many plants. We introduced the chromosomal regions containing the dormancy QTLs $q S D 1, q S D 7-1$, and qSD12 from an accession of weedy rice into a nondormant genetic background to examine component genetic effects and their interactions with time of afterripening (DAR). A $\mathrm{BC}_{4} \mathrm{~F}_{2}$ plant, which was heterozygous for the three loci, was selected to develop the $\mathrm{BC}_{4} \mathrm{~F}_{3}$ population. Single point analysis detected only $q S D 7-1$ and $q S D 12\left(R^{2}=38-72 \%\right)$ at 10,30 , and 50 DAR in the population. However, multiple linear regression analysis detected genetic effects of the three QTLs and their trigenic epistasis, an environmental effect of DAR (E), and interactions of $E$ with $q S D 12$ and with the $q S D 1 \times q S D 7-1$ and $q S D 7-1 \times q S D 12$ epistases. The
\end{abstract}

linear model demonstrates that QTL main effects varied with DAR, and that some epistasis or epistasis-by-DAR interactions partially counteract the main effects. The three QTLs were isolated as single Mendelian factors from the $\mathrm{BC}_{4} \mathrm{~F}_{3}$ population and estimated for component genic effects based on the $\mathrm{BC}_{4} \mathrm{~F}_{4}$ populations. Isolation improved estimation of the $q S D 1$ effect and confirmed the major effect of $q S D 12$. The $q S D 1$ and $q S D 12$ loci displayed a gene-additive effect. The $q S D 7-1$, which was further narrowed to a chromosomal region encompassing the red pericarp color gene $R c$, displayed gene additive and dominant effects.

Heredity (2006) 96, 93-99. doi:10.1038/sj.hdy.6800757; published online 28 September 2005

Keywords: seed dormancy; afterripening; Mendelian factor; genetic model; genic effects; quantitative trait locus

\section{Introduction}

The polygenic nature of seed dormancy determines the continuous distribution over time for germination in natural and experimental populations (Johnson, 1935). A complete linkage map enables genome-wide scanning for polygenes or quantitative trait loci (QTLs) and manipulation of individual alleles for experimentation or breeding. Many dormancy QTLs have been identified from model plants and major cereal crops. For example, dormancy QTLs are distributed over all five chromosomes (chr) in Arabidopsis (Arabidopsis thaliana) (Van der Schaar et al, 1997; Alonso-Blanco et al, 2003; Clerkx et al, 2004) and 11 of the $12 \mathrm{chr}$ in cultivated (Oryza sativa) (Wan et al, 1997; Lin et al, 1998; Dong et al, 2002; Miura et al, 2002), wild (O. rufipogon) (Cai and Morishima, 2000; Thomson et al, 2003), and weedy (O. sativa) (Gu et al, 2004) rice. Dormancy QTLs in barley (Oberthur et al, 1995; Li et al, 2003; Prada et al, 2004), sorghum (Lijavetzky et al, 2000), and wheat (Anderson et al, 1993; Kato et al, 2001; Mares and Mrva, 2001; Groos et al, 2002; Osa et al, 2003; Kulwal et al, 2004) have been identified to seek gene resources to impart resistance to preharvest sprouting (PHS) and to manipulate germination programs in the malting process. Additional research has been aimed at isolation of individual dormancy alleles from donor parents to determine gene effects, interactions with environmental factors, and breeding potential.

Correspondence: ME Foley, Biosciences Research Laboratory, USDA ARS, Fargo, ND 58105-5674, USA. E-mail: foleym@fargo.ars.usda.gov Received 21 April 2005; accepted 15 August 2005; published online 28 September 2005
Several dormancy QTL regions have been isolated in introgression or near isogenic lines for Arabidopsis, barley, and rice (Han et al, 1999; Alonso-Blanco et al, 2003; Gao et al, 2003; Takeuchi et al, 2003). Fine mapping these regions suggests: (1) a dormancy QTL may consist of a gene cluster (Han et al, 1999); (2) some dormancy QTLs may lose their effect in a nondormant genetic background (Alonso-Blanco et al, 2003); (3) some QTLs are especially sensitive to the environment during seed development (Gao et al, 2003); and (4) an influence of flowering time on dormancy may be due to tight linkage between loci for both traits (Takeuchi et al, 2003). Some of the introgression lines were used to estimate geneadditive effects for the QTL. Many genetic analyses suggest some dormancy genes may also consist of genedominant effects (Johnson, 1935; Takahashi, 1962; Bhatt et al, 1983; Buraas and Skinnes, 1984). These observations must be confirmed with the populations segregating for individual QTLs, or Mendelian factors. The major obstacle to the confirmation is that most dormancy QTLs contributed relatively little to phenotypic variance such that it is difficult to distinguish a component gene effect from environmental error.

Dormancy is released by afterripening, which is defined by a period of seed exposure to a set of environmental conditions after maturation and separation from the parent plant (Simpson, 1990). Environmental conditions that facilitate afterripening vary by species. For example, rice normally requires afterripening under warm, dry conditions (Leopold et al, 1988) and Arabidopsis responds best to cool, moist conditions (Koornneef and Karssen, 1994). Rice species (Oryza ssp) differ in patterns of afterripening under warm, dry 
conditions (Veasey et al, 2004). Some dormancy QTLs in cultivated rice lost their effect upon drying (Lin et al, 1998). Dormancy QTLs identified from weedy rice could be grouped into relatively early, constant, and late expression categories during afterripening ( $\mathrm{Gu}$ et al, 2004), which was similar to that from Arabidopsis (Alonso-Blanco et al, 2003). Thus, time of afterripening is an important environmental factor affecting expression of dormancy genes.

Previous research identified six dormancy QTLs from an accession of weedy rice (Gu et al, 2004). Subsequent research transferred five dormancy QTLs into a nondormant breeding line by phenotypic and markerassisted selections (Gu et al, 2005). In this research, we synchronized the genetic background of three dormancy QTLs to develop a genetic model involving the genotypic (G) and genotype-by-environmental (time of afterripening) $(\mathrm{G} \times \mathrm{E})$ interaction effects, and then isolated individual loci as single Mendelian factors to estimate component gene effects.

\section{Materials and methods}

Developing heterozygotes for $q S D 1, q S D 7-1$, and $q S D 12$ Phenotypic and marker-assisted selections were used to develop a trigenic heterozygote for the loci $q S D 1, q S D 7-1$, and $q S D 12$, where the dormancy alleles were derived from the weedy rice SS18-2 (Gu et al, 2003). Initially, five generations of single-plant selection for dormancy and recurrent backcrossing introduced several SS18-2-derived chr segments into the genetic background of EM93-1, a nondormant, early maturation breeding line. Then, the framework linkage map (Gu et al, 2004) was used to scan for the introgression segments in selected $\mathrm{BC}_{4} \mathrm{~F}_{1}$ plants, and to select a genotype carrying dormancy alleles at all three QTLs from a $\mathrm{BC}_{4} \mathrm{~F}_{2}$ population ( $\mathrm{Gu}$ et al, 2005). Finally, we selected $\mathrm{BC}_{4} \mathrm{~F}_{2}$ plant \#51, as it was heterozygous for the qSD1-, qSD7-1-, and $q S D 12$-containing regions, and the remaining $\mathrm{chr}$ or chr segments were identical to EM93-1 (Figure 1). $\mathrm{BC}_{4} \mathrm{~F}_{2}$ plant \#51 was self-pollinated to generate the $\mathrm{BC}_{4} \mathrm{~F}_{3}$ population to develop a genetic model involving the three QTLs, the time (days) of afterripening (DAR), and their interactions.

Molecular markers in the three QTL regions (Figure 1) were used to select single-locus heterozygotes from the $\mathrm{BC}_{4} \mathrm{~F}_{3}$ population. The selected plants carried only a single dormancy allele at one of the three QTLs, as judged by its nearest and flanking markers (Table 1). For each QTL, we selected two $\mathrm{BC}_{4} \mathrm{~F}_{3}$ plants that differed in length of the introgressed QTL segment, but shared the region encompassing the nearest markers (Table 1). These six $\mathrm{BC}_{4} \mathrm{~F}_{3}$ heterozygotes were self-pollinated to generate $\mathrm{BC}_{4} \mathrm{~F}_{4}$ segregation populations to estimate gene additive and dominant effects for individual QTLs.

\section{Plant cultivation and dormancy assessment}

Plants were grown in pots $(28 \mathrm{~cm}$ diameter $\times 25 \mathrm{~cm}$ height) filled with a mixture of clay soil and SUNSHINE medium (Sun Gro ${ }^{\circledR}$ Horticulture Canada Ltd, Seba Beach, $\mathrm{AB}$ ) and watered daily. The six $\mathrm{BC}_{4} \mathrm{~F}_{4}$ populations were maintained in one greenhouse. Day/night temperatures were set at $29 / 21^{\circ} \mathrm{C}$ and the daylength set for $14 \mathrm{~h}$. Seeds were harvested at 40 days after flowering,
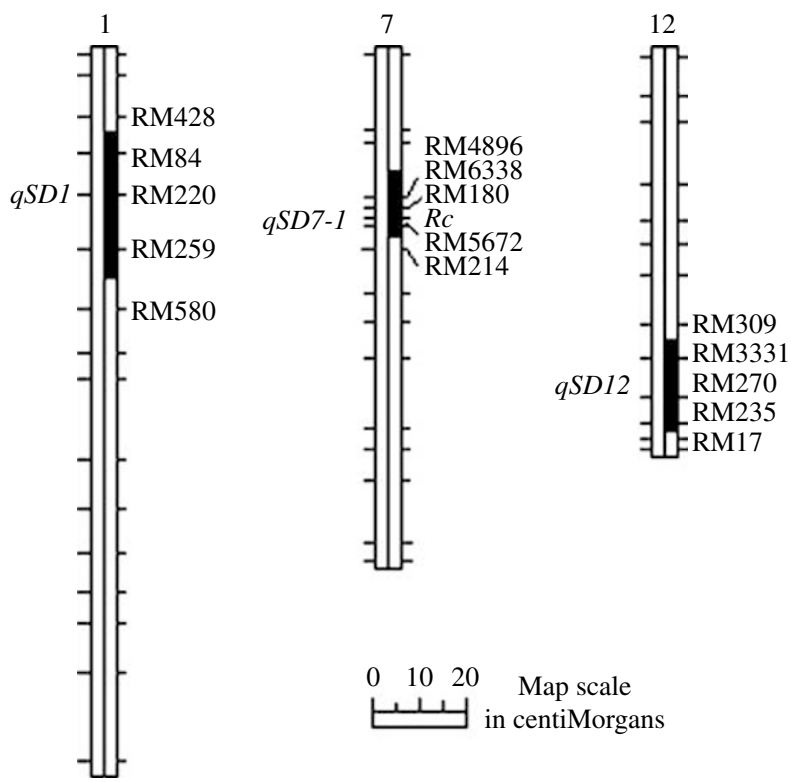

Figure 1 Graphic genotypes for chromosomes 1,7 , and 12 of $\mathrm{BC}_{4} \mathrm{~F}_{2}$ plant \#51. Empty or solid bars denote the EM93-1- or SS18-2-derived chromosomes or chromosomal segments, respectively, which were determined by rice microsatellite (RM) markers at the tick mark positions on the framework linkage map ( $\mathrm{Gu}$ et al, 2004); chromosomes not shown were identical to EM93-1. QTLs for seed dormancy $(q S D)$ are placed to the left of segments.

Table 1 Dormancy allele flanking regions and germination of the selected $\mathrm{BC}_{4} \mathrm{~F}_{3}$ plants

\begin{tabular}{|c|c|c|c|c|c|c|}
\hline \multirow[t]{2}{*}{$B C_{4} F_{3}$ plant $^{\mathrm{a}}$} & \multirow[t]{2}{*}{$Q T L$} & \multirow[t]{2}{*}{ Chromosomal segment ${ }^{\mathrm{b}}$} & \multicolumn{3}{|c|}{ Percent germination at days of afterripening } & \multirow[t]{2}{*}{$\mathrm{BC}_{4} \mathrm{~F}_{4}$ population } \\
\hline & & & 10 & 30 & 50 & \\
\hline \#66 & $q S D 1$ & RM84-RM259 & 26.1 & 93.1 & 97.7 & 61 \\
\hline${ }^{* 159}$ & qSD1 & RM220-RM259 & 35.9 & 92.3 & 100 & 108 \\
\hline "12 & $q S D 7-1$ & RM6338-RM5672 & 16.8 & 91.7 & 99.0 & 126 \\
\hline \#114 & qSD7-1 & $R_{c}-\mathrm{RM} 5672$ & 25.5 & 91.2 & 99.3 & 75 \\
\hline \#48 & qSD12 & RM3331-RM235 & 32.1 & 82.1 & 94.7 & 74 \\
\hline \#145 & $q S D 12$ & RM3331-RM270 & 32.6 & 86.9 & 98.1 & 110 \\
\hline \multicolumn{3}{|c|}{ Means $\pm S D$ for the $\mathrm{BC}_{4} \mathrm{~F}_{3}$ population } & $15 \pm 16$ & $57 \pm 29$ & $73 \pm 27$ & \\
\hline
\end{tabular}

${ }^{\mathrm{a}}$ Genotype is heterozygous for a dormancy QTL-containing interval.

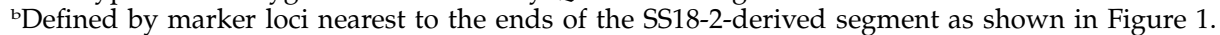

${ }^{\mathrm{c}}$ Number of plants assayed for marker genotype and germination in the $\mathrm{BC}_{4} \mathrm{~F}_{3}$ plant-derived $\mathrm{BC}_{4} \mathrm{~F}_{4}$ population. 
which was tagged by emergence of the first panicle in the plant. Seeds were cleaned by removal of empty or immature spikelets and air-dried in the greenhouse for 3 days to about $12 \%$ moisture. Dried seeds were sealed in plastic containers and stored at $-20^{\circ} \mathrm{C}$ to prevent afterripening.

The degree of dormancy was measured with percent germination. Prior to germination, seeds from the $\mathrm{BC}_{4} \mathrm{~F}_{3}$ population were afterripened at the room temperature (about $25^{\circ} \mathrm{C}$ ) for 10,30 , and 50 days; the time interval was determined based on germination for the $\mathrm{BC}_{4} \mathrm{~F}_{2}$ population $\left(\mathrm{Gu}\right.$ et al, 2005). Seeds from the six $\mathrm{BC}_{4} \mathrm{~F}_{4}$ populations were afterripened for 1 or 7 , and 14 days. A shorter period of afterripening was applied to the $\mathrm{BC}_{4} \mathrm{~F}_{4} \mathrm{~S}$ because more that $80 \%$ of the $\mathrm{BC}_{4} \mathrm{~F}_{3}$ parental plant seeds germinated following $<30$ DAR (Table 1). There were three replications per experiment, with each replication consisting of approximately 50 seeds in a 9-cm Petri dish lined with a Whatman No.1 filter paper and wetted with 10-ml deionized water (Roberts, 1961; Gu et al, 2003). Germination was conducted at $30^{\circ} \mathrm{C}$ and $100 \%$ relative humidity in the dark for 7 days. Germination was evaluated visually by protrusion of the radicle or coleoptile from the hull by $\geq 3 \mathrm{~mm}$. Germination percentage $(y)$ was transformed by $\sin ^{-1}(y)^{-0.5}$ and the mean averaged over the three replications at each DAR was used for QTL analysis.

\section{Genotypic identification and QTL effect analyses}

The $\mathrm{BC}_{4} \mathrm{~F}_{3}$ and $\mathrm{BC}_{4} \mathrm{~F}_{4}$ plants were genotyped with microsatellite (RM) markers on the SS18-2-derived segments (Figure 1). Genomic DNA was prepared from young leaves. The DNA was extracted, markers amplified by polymerase chain reaction (PCR), and the PCR products displayed using the methods previously described (Gu et al, 2004). The partial linkage map was adjusted with MAPMAKER/EXP 3.0 (Lincoln et al, 1992).

Dormancy QTL epistases and $q S D 12 \times$ DAR were detected in the primary segregation population $(\mathrm{Gu}$ et al, 2004). There are four factors (ie, qSD1, qSD7-1, $q S D 12$, and time of afterripening) and their interactions regulating phenotypic variation in germination in the $\mathrm{BC}_{4} \mathrm{~F}_{3}$ population because the genetic background of three QTLs has been synchronized (Figure 1). Thus, multiple-linear regression was used to estimate the relative importance of component QTL genotypic (G) and $G \times E$ interaction effects using the model:

$$
\begin{aligned}
y_{i j}= & m+b_{1} x_{1}+b_{2} x_{2}+b_{3} x_{3}+b_{12} x_{12}+b_{13} x_{13}+b_{23} x_{23} \\
& +b_{123} x_{123}+b_{\mathrm{t}} x_{\mathrm{t}}+b_{1 \mathrm{t}} x_{1 \mathrm{t}}+b_{2 \mathrm{t}} x_{2 \mathrm{t}}+b_{3 \mathrm{t}} x_{3 \mathrm{t}}+b_{12 \mathrm{t}} x_{12 \mathrm{t}} \\
& +b_{13 \mathrm{t}} x_{13 \mathrm{t}}+b_{23 \mathrm{t}} x_{23 \mathrm{t}}+b_{123 \mathrm{t}} x_{123 \mathrm{t}}+e_{i j} \\
& (i=1-N ; j=1,2 \text {, and } 3),
\end{aligned}
$$

where, $y_{i j}$ is the mean germination for the $i$ th $\mathrm{BC}_{4} \mathrm{~F}_{3}$ plant in the $j$ th afterripening treatment $(j=1,2$, and 3 corresponding to 10,30 , and 50 DAR, respectively); $m$ is the mean of the model; $x_{1}, x_{2}$, and $x_{3}$ are the variables for codominant markers nearest to qSD1, qSD7-1, and qSD12, respectively, where EM93-1-type homozygous, heterozygous, and SS18-2-type homozygous genotypes for each marker were scored as $-1,0$, and 1, respectively; $x_{12}, x_{13}$, and $x_{23}$ are the digenic interactions between variables $x_{1}$ and $x_{2}, x_{1}$ and $x_{3}$, and $x_{2}$ and $x_{3}$, respectively; $x_{123}$ is the trigenic interaction among the three QTLs; $x_{\mathrm{t}}$ is the variable for afterripening treatment; $x_{1 \mathrm{t}}, x_{2 \mathrm{t}}, x_{3 \mathrm{t}}, x_{12 \mathrm{t}}$, $x_{13 \mathrm{t}}, x_{23 \mathrm{t}}$, and $x_{123 \mathrm{t}}$ are the interactions between time of afterripening and the variables $x_{1}, x_{2}, x_{3}, x_{12}, x_{13}, x_{23}$, and $x_{123}$, respectively; $b_{1}, b_{2}, b_{3}, b_{12}, b_{13}, b_{23}, b_{123}, b_{\mathrm{t}}, b_{1 \mathrm{t}}, b_{2 \mathrm{t}}, b_{3 \mathrm{t}}$ $b_{12 \mathrm{t}}, b_{13 \mathrm{t}}, b_{23 \mathrm{t}}$, and $b_{123 \mathrm{t}}$ are the partial regression coefficients corresponding to the regressor variables $x_{1}$, $x_{2}, x_{3}, x_{12}, x_{13}, x_{23}, x_{123}, x_{\mathrm{t}}, x_{1 \mathrm{t}}, x_{2 \mathrm{t}}, x_{3 \mathrm{t}}, x_{12 \mathrm{t}}, x_{13 \mathrm{t}}, x_{23 \mathrm{t}}$ and $x_{123 t}$, respectively; $e_{i j}$ is the random error in the experiment conditions; and $N(N=213-221)$ is the number of $\mathrm{BC}_{4} \mathrm{~F}_{3}$ plants that were evaluated for germination at a DAR. Analysis was performed by the SAS procedure REG (SAS Institute, 1999). The variables retained in the final model were determined by a stepwise selection at a significant level of $5 \%$.

One-way ANOVA was used to estimate the contribution of individual QTLs to phenotypic variance in germination at different $\mathrm{DAR}$ in $\mathrm{BC}_{4} \mathrm{~F}_{3}$ and $\mathrm{BC}_{4} \mathrm{~F}_{4}$ populations. The analysis was based on the linear model in which a phenotypic value was partitioned into mean, genotypic, and error (also including genetic effects that are not explained by the QTL for the $\mathrm{BC}_{4} \mathrm{~F}_{3}$ population) components. The contribution $\left(R^{2}\right)$ of each QTL was calculated as the proportion of component type III sumof-square (SS) to the corrected total SS. ANOVA was performed with the SAS procedure GLM (SAS Institute, 1999).

Component additive (a) and dominant $(d)$ effects of a dormancy QTL were estimated based on the $\mathrm{BC}_{4} \mathrm{~F}_{4}$ populations. Each $\mathrm{BC}_{4} \mathrm{~F}_{4}$ segregated for one QTLcontaining region. Thus, the method described by Kearsey and Pooni (1996) is well suited for the estimations:

$$
\begin{aligned}
& a=\frac{1}{2} M_{\mathrm{SS}}-\frac{1}{2} M_{\mathrm{EE}} \\
& d=M_{\mathrm{ES}}-\frac{1}{2} M_{\mathrm{EE}}-\frac{1}{2} M_{\mathrm{SS}}
\end{aligned}
$$

where, $M_{\mathrm{EE}}, M_{\mathrm{SS}}$, and $M_{\mathrm{ES}}$ are means of the EM93-1-type homozygous, SS18-2-type homozygous, and heterozygous genotypes, respectively, for the marker locus nearest to the QTL. SE for the parameters $a$ and $d$ were estimated as:

$$
\begin{aligned}
& s_{a}=\frac{1}{2}\left(s_{\mathrm{EE}}^{2}+s_{\mathrm{SS}}^{2}\right)^{1 / 2} \\
& s_{d}=\left(s_{\mathrm{ES}}^{2}+\frac{1}{4} s_{\mathrm{EE}}^{2}+\frac{1}{4} s_{\mathrm{SS}}^{2}\right)^{1 / 2}
\end{aligned}
$$

where, the $s_{\mathrm{EE}}^{2}, s_{\mathrm{SS}}^{2}$, and $s_{\mathrm{ES}}^{2}$ are variances of the means $M_{\mathrm{EE}}, M_{\mathrm{SS}}$, and $M_{E S}$, respectively. Significance of the estimates for $a$ and $d$ were determined by Student's $t$-test.

\section{Results}

\section{A genetic model for three dormancy QTLs and time of afterripening}

The $\mathrm{BC}_{4} \mathrm{~F}_{3}$ population skewed to low and high germination at 10 and 50 DAR, respectively, and distributed over the whole germination scale at 30 DAR (Figure 2). Oneway ANOVA detected only the qSD7-1 and $q S D 12$ loci (Figure 2). These two QTLs displayed divergent responses to time of afterripening. For example, qSD7-1 accounted for 18 and 5\%, while $q S D 12$ explained 38 and $72 \%$ of the phenotypic variance at 10 and 50 DAR, respectively. Locus $q S D 1$ was not detected in this single 
point analysis, indicating that there must be something masking its main effect under the experimental conditions.

The multiple linear regression analysis detected eight variables significantly contributing to variation in germination (Table 2). The linear relationship of the eight variables accounted for $82 \%$ of the total variance. These variables can be grouped into three categories, that is, genotypic, environmental, and $\mathrm{G} \times \mathrm{E}$ effects. The genotypic effect includes the main effect of the three QTLs and their trigenic epistatic effect. As indicated by sign and magnitude of the partial regression coefficients $(b)$, substitution of a nondormancy allele with a dormant allele at any of the three QTLs tended to reduce germination, with the effect $\left(b_{2}, b_{3}=-0.12\right.$ to -0.13$)$ of the qSD7-1 and qSD12 dormancy alleles being much greater than that $\left(b_{1}=-0.04\right)$ of the $q S D 1$ dormancy allele. In contrast to the QTL main effects, interaction among the three QTLs tended to promote germination, although the magnitude was relatively small $\left(b_{123}=0.06\right)$.

The environmental effect in the experimental conditions was caused by differences in DAR. An increase in time of afterripening under warm, dry conditions greatly promoted germination of dormant seeds $\left(b_{\mathrm{t}}=0.32\right)$, or dramatically shifted the germination distribution

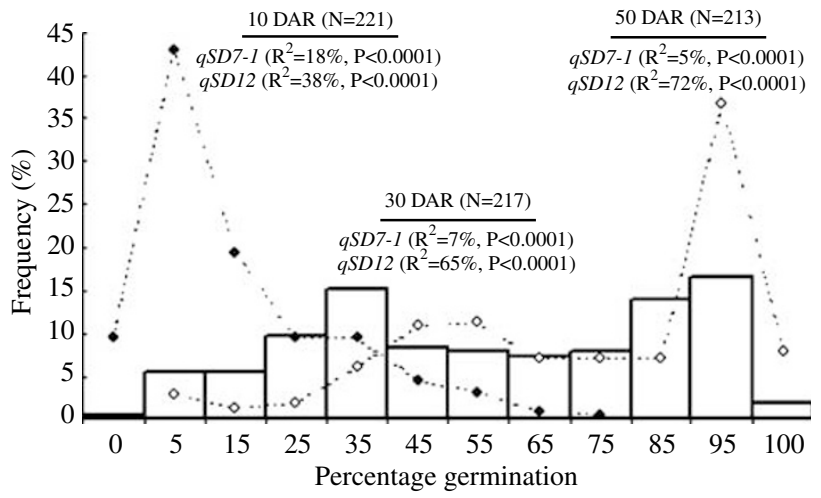

Figure 2 Frequency distribution of the $\mathrm{BC}_{4} \mathrm{~F}_{3}$ population for percentage germination at $10(\bullet), 30$ (open columns), and $50(\bigcirc)$ days of afterripening (DAR). Sample size $(N)$, and proportion of the phenotypic variance explained by $q S D 7-1$ and $q S D 12\left(R^{2}\right)$ are shown in parentheses.
(Figure 2). The $\mathrm{G} \times \mathrm{E}$ effect includes the interactions of time of afterripening with: (1) the major locus $q S D 12,(2)$ the $q S D 7-1 \times q S D 12$ epistasis, and (3) the $q S D 7-1 \times q S D 1$ epistasis (Table 2 ). The $q S D 12 \times \mathrm{E}$ interaction $\left(b_{3 \mathrm{t}}=-0.15\right)$ accounted for a high proportion of the great increase in the $q S D 12$ major effect with progression of afterripening (Figure 2). The digenic epistases of $q S D 7-1 \times q S D 12$ $\left(b_{23}=-0.05\right)$ and $q S D 1 \times q S D 7-1\left(b_{12}=0.01\right)$ displayed a decreasing and an increasing effect on germination with time of afterripening during the 50 DAR. These component $\mathrm{G} \times \mathrm{E}$ interactions explained the asymmetry distributions of germination (Figure 2).

\section{Single-locus models for dormancy QTLs}

The isolated $q S D 1, q S D 7-1$, and $q S D 12$ had significant effects on germination (Table 3 ). The three QTLs differed in gene component effects. Locus qSD1 accounted for about 7 and $12 \%$ of the phenotypic variances, respectively, at 7 and 14 DAR in both $\mathrm{BC}_{4} \mathrm{~F}_{4}$ (66) and (159) populations. The gene-additive component explained the genetic effect of $q S D 1$, as its dominant effect was not significantly different relative to experimental error (Table 3).

The locus qSD7-1 accounted for $11-16 \%$ of the phenotypic variances at 1-14 DAR in the $\mathrm{BC}_{4} \mathrm{~F}_{4}$ (12) and (114) populations. Both gene additive and dominant effects were important for qSD7-1, based on the codominant marker RM5672 (Table 3). The $\mathrm{BC}_{4} \mathrm{~F}_{4}$ (12) and (114) populations also segregated for the red pericarp color gene $R c$, a dominant marker (Figure $3 b$ ). The $R c$ locus was about $2 \mathrm{cM}$ from RM5672 and contributed $13-18 \%$ to phenotypic variance at $1-14$ DAR in the two populations. The slightly larger contribution to phenotypic variance of the $R c$ locus compared with the RM5672 locus, and the significant dominant effect for $q S D 7-1$ suggest that $R c$ is closer to qSD7-1 than to RM5672.

The locus $q$ SD12 accounted for about 67 and $50 \%$ of the phenotypic variances at 7 and 14 DAR, respectively, in the $\mathrm{BC}_{4} \mathrm{~F}_{4}$ (48) and (145) populations. This is a major dormancy QTL as compared with qSD1 and qSD7-1. A gene additive effect explained the genetic effect of this major QTL; the component dominant effect was insignificant or relatively minor (Table 3 ).

Table 2 Variables retained by multiple linear regression analysis based on the $\mathrm{BC}_{4} \mathrm{~F}_{3}$ population ${ }^{\mathrm{a}}$

\begin{tabular}{|c|c|c|c|c|c|}
\hline Variables $^{\mathrm{b}}$ & Degree of freedom & Partial regression coefficient $(\mathrm{b})$ & Standard error & $\mathrm{t}$-value & Probability \\
\hline$x_{1}$ & 1 & -0.0385 & 0.0108 & -3.55 & 0.0004 \\
\hline$x_{2}$ & 1 & -0.1368 & 0.0117 & -11.72 & $<0.0001$ \\
\hline$x_{3}$ & 1 & -0.1194 & 0.0320 & -3.73 & 0.0002 \\
\hline$x_{123}\left(x_{1} \times x_{2} \times x_{3}\right)$ & 1 & 0.0596 & 0.0225 & 2.65 & 0.0082 \\
\hline$x_{\mathrm{t}}$ & 1 & 0.3225 & 0.0109 & 29.62 & $<0.0001$ \\
\hline$x_{3 t}\left(x_{3} \times x_{t}\right)$ & 1 & -0.1464 & 0.0150 & -9.77 & $<0.0001$ \\
\hline$x_{12 \mathrm{t}}\left(x_{1} \times x_{2} \times x_{\mathrm{t}}\right)$ & 1 & 0.0140 & 0.0069 & 2.01 & 0.0444 \\
\hline$x_{23 \mathrm{t}}\left(x_{2} \times x_{3} \times x_{\mathrm{t}}\right)$ & 1 & -0.0501 & 0.0081 & -6.18 & $<0.0001$ \\
\hline Total & 8 & Determination coefficient $\left(R^{2}\right)$ & & & \\
\hline
\end{tabular}

aSee Materials and methods for the linear model.

'Variables $x_{1}, x_{2}, x_{3}$, and $x_{\mathrm{t}}$ stand for $q S D 1, q S D 7-1, q S D 12$, and time of afterripening, respectively. The nondormant homozygote, heterozygote, and dormant homozygote at each QTL were coded as $-1,0$, and 1, respectively, and the 10, 30, and 50 days of afterripening coded as 1,2 , and 3 , respectively for analysis. 
Table 3 Genic effects of dormancy QTLs on germination at different days of afterripening (DAR) based on the BC $\mathrm{F}_{4}$ populations segregating for individual loci

\begin{tabular}{|c|c|c|c|c|c|c|}
\hline$Q T L^{\mathrm{a}}$ & $D A R$ & $\mathrm{R}^{2}(\%)^{\mathrm{b}}$ & Probability $^{\mathrm{b}}$ & $a^{\mathrm{c}}$ & $d^{c}$ & Populations $^{\mathrm{d}}$ \\
\hline \multirow[t]{4}{*}{ qSD1 (RM220) } & 7 & 6.7 & 0.0148 & $-0.097^{*}$ & $0.058^{\mathrm{NS}}$ & $\mathrm{BC}_{4} \mathrm{~F}_{4}(66)$ \\
\hline & & 8.1 & 0.0394 & $-0.091^{*}$ & $-0.040^{\mathrm{NS}}$ & $\mathrm{BC}_{4} \mathrm{~F}_{4}(159)$ \\
\hline & 14 & 11.1 & 0.0470 & $-0.101^{*}$ & $-0.080^{\mathrm{NS}}$ & $\mathrm{BC}_{4} \mathrm{~F}_{4}(66)$ \\
\hline & & 14.4 & 0.0208 & $-0.105^{*}$ & $0.019^{\mathrm{NS}}$ & $\mathrm{BC}_{4} \mathrm{~F}_{4}(159)$ \\
\hline \multirow[t]{5}{*}{ qSD7-1 (RM5672) } & 1 & 12.5 & 0.0010 & $-0.038^{*}$ & $-0.064^{* *}$ & $\mathrm{BC}_{4} \mathrm{~F}_{4}(12)$ \\
\hline & & 16.2 & $<0.0001$ & $-0.086^{* *}$ & $-0.056^{* *}$ & $\mathrm{BC}_{4} \mathrm{~F}_{4}(114)$ \\
\hline & 7 & 11.3 & $<0.0001$ & $-0.081^{*}$ & $-0.098^{*}$ & $\mathrm{BC}_{4} \mathrm{~F}_{4}(114)$ \\
\hline & 14 & 13.4 & 0.0001 & $-0.099^{* *}$ & $-0.077^{*}$ & $\mathrm{BC}_{4} \mathrm{~F}_{4}(12)$ \\
\hline & & 10.7 & 0.0168 & $-0.022^{\mathrm{NS}}$ & $-0.157^{* *}$ & $\mathrm{BC}_{4} \mathrm{~F}_{4}(114)$ \\
\hline \multirow[t]{4}{*}{ qSD12 (RM270) } & 7 & 66.0 & $<0.0001$ & $-0.338^{* * *}$ & $0.016^{\mathrm{NS}}$ & $\mathrm{BC}_{4} \mathrm{~F}_{4}(48)$ \\
\hline & & 67.8 & $<0.0001$ & $-0.299^{* * *}$ & $-0.013^{\mathrm{NS}}$ & $\mathrm{BC}_{4} \mathrm{~F}_{4}(145)$ \\
\hline & 14 & 54.5 & $<0.0001$ & $-0.278^{* * *}$ & $-0.002^{\mathrm{NS}}$ & $\mathrm{BC}_{4} \mathrm{~F}_{4}(48)$ \\
\hline & & 48.5 & $<0.0001$ & $-0.273^{* * *}$ & $-0.039^{\mathrm{NS}}$ & $\mathrm{BC}_{4} \mathrm{~F}_{4}(145)$ \\
\hline
\end{tabular}

aMarkers in parentheses were used to estimate contributions $\left(R^{2}\right)$ and genic effects.

bProportion of the phenotypic variance explained by the QTL and the F-test probability computed by one-way ANOVA.

${ }^{\mathrm{C}}$ Gene additive $(a)$ and dominant $(d)$ effects; the letters ns or asterisks indicate the effects are not significant (NS) or significant at the $P=0.05$ $(*), 0.01(* *)$, or $<0.001(* *)$ probability levels.

${ }^{\mathrm{d} N u m b e r s}$ in the parentheses indicate the $\mathrm{BC}_{4} \mathrm{~F}_{3}$ plants selected to develop the $\mathrm{BC}_{4} \mathrm{~F}_{4}$ populations (see Table 1).

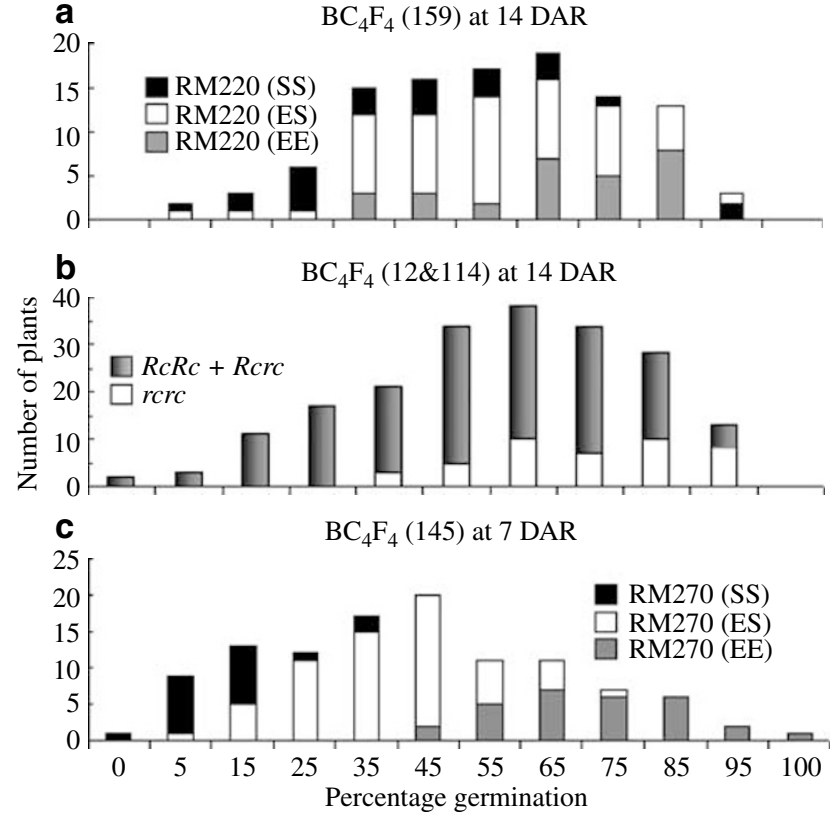

Figure 3 Distribution of germination at 7 or 14 days of afterripening (DAR) for populations segregating for qSD1 (a), qSD7-1 (b), and $q S D 12$ (c). The bars depicted genotypes for the marker nearest a QTL. RM220 and RM270 are codominant markers, and Rc is a dominant marker gene for red pericarp/testa color.

\section{Discussion}

The model developed based on the $\mathrm{BC}_{4} \mathrm{~F}_{3}$ population includes all three dormancy QTLs and their epistasis, time of afterripening, and interactions between time of afterripening and QTL or epistasis (Table 2). This multiple linear model provides insight into how a set of dormancy genes regulates germination of seeds afterripened under warm, dry conditions. The genetic effect of three dormancy loci can be partitioned into linear and nonlinear components. The linear components delay or repress germination. The nonlinear component may partially counterbalance the linear effects on germination. In the $\mathrm{BC}_{4} \mathrm{~F}_{3}$ genetic background, only trigenic epistasis was significant, and other significant epistases involved interactions with time of afterripening $(G \times E)$. In several ways, epistases and $G \times E$ interactions indicate the complexity in regulation of germination or detection of dormancy genes. First, only part of a QTL effect is independent of time of afterripening, a substantial remaining amount involved epistases and/or $\mathrm{G} \times \mathrm{E}$ interactions (Table 2). Second, some epistatic and $\mathrm{G} \times \mathrm{E}$ interaction effects enhance dormancy, while others may partially counteract a QTL main effect $(\mathrm{Gu}$ et al, 2004; Table 2). Finally, the main effect of a QTL, especially one with a relatively small effect, could be masked by gene or gene-by-E interactions. For example, qSD1 was detected in the synchronized genetic background, that is, the two $\mathrm{BC}_{4} \mathrm{~F}_{4}$ populations (Table 3 ), but not in the primary segregation population ( $\mathrm{Gu}$ et al, 2004), one of the $\mathrm{BC}_{4} \mathrm{~F}_{2}$ populations ( $\mathrm{Gu}$ et al, 2005), and the $\mathrm{BC}_{4} \mathrm{~F}_{3}$ population (Figure 2).

We isolated three dormancy QTLs as Mendelian factors. The three genotypes for a QTL, no matter how large a QTL's effect on germination, displayed overlapping rather than discrete distributions, as estimated by nearest markers (Figures $3 a-c$ ). If possible rare recombinants between a QTL and its nearest marker are ignored, the continuous variation within each marker genotype must have arisen from environmental variation, because the genetic background was synchronized. The environmental (within-genotype) variance appeared inversely proportional to the component genetic variance in percentage germination in populations segregating for 
a single dormancy gene. For example, genetic and environmental variances accounted for a smaller (14\%) and larger $(86 \%)$ amount, respectively, of the total variance in germination at $14 \mathrm{DAR}$ in the $\mathrm{BC}_{4} \mathrm{~F}_{4}$ (159) population segregating for $q S D 1$, and a larger $(68 \%)$ and smaller $(32 \%)$ amount, respectively, of the total variance in germination at $7 \mathrm{DAR}$ in the $\mathrm{BC}_{4} \mathrm{~F}_{4}$ (145) population segregating for $q S D 12$ (Table 3 ). The inverse proportionality occurred even in isogenic lines because total variance in different populations can reach a similar level by adjusting the time of afterripening (Figure 3) when dormancy is quantified by percent germination ( $\mathrm{Gu}$ et al, 2003). It was reported that heritability for dormancy in rice cultivars was $0.12-0.44$ (Chang and Yen, 1969), and the range of within-parental line variation in germination was similar to that of the $F_{2}$ population cultivated under field conditions (Chang and Tagumpay, 1973). The low heritability for dormancy or large environmental variation in dormancy makes it very difficult to manipulate individual dormancy alleles. For example, we were unable to isolate and distinguish the three QTLs without use of linked markers, as the selected $\mathrm{BC}_{4} \mathrm{~F}_{3}$ plants had similar germination (Table 1). Thus, a marker-assisted selection technique will be important to integrate dormancy genes into new varieties to impart resistance to PHS.

We purposely selected two $\mathrm{BC}_{4} \mathrm{~F}_{3}$ plants for each QTL that differed in interval length (Table 1) to narrow the region flanking dormancy alleles. The $R c$ locus was mapped between RM180 and RM5672 (Figure 1). Both $\mathrm{BC}_{4} \mathrm{~F}_{3}$ plants ${ }^{\# 12}$ and ${ }^{\# 114}$ carry the $q S D 7-1$ and $R c$ loci according to segregation data from their $\mathrm{BC}_{4} \mathrm{~F}_{4}$ populations (Figure $3 b$ ), but plant " 114 has a much shorter SS182-derived chr segment (between RM180 and RM241) than plant ${ }^{\# 12}$ (between RM4896 and RM214) (Table 1 and Figure 1). The $R c$ locus contributed a few percent more to phenotypic variances in germination than the RM5672 and RM180 loci in the $\mathrm{BC}_{4} \mathrm{~F}_{4}$ (12) and (114) populations, suggesting that $q S D 7-1$ locates on the same $4 \mathrm{cM}$ chr segment as $R c$. In addition, $R c$ is dominant; the qSD7-1 locus also had a dominant effect (Table 3). The tight linkage and the gene-dominant effect suggest that $R c$ and $q S D 7-1$ might be the same locus. Red grain color gene has long been associated with dormancy in wheat and the association has been hypothesized as a pleiotropic effect of the homoelogous red color genes (R1-R3) (Nilsson-Ehle, 1914; Gfeller and Svejda, 1960; Flintham, 2000). Map-based cloning of the $q S D 7-1-R c$ region will test the hypothesis using rice.

\section{Acknowledgements}

We thank B Hoffer, T Nelson, and C Kimberlin for technical assistance. Funding for this work was provided by USDA-National Research Initiative (0200668).

\section{References}

Alonso-Blanco C, Bentsink L, Hanhart CJ, Vries HBE, Koornneef $M$ (2003). Analysis of natural allelic variation at seed dormancy loci of Arabidopsis thaliana. Genetics 164: 711-729.

Anderson JA, Sorrells ME, Tanksley SD (1993). RFLP analysis of genomic regions associated with resistance to pre-harvest sprouting in wheat. Crop Sci 33: 453-459.
Bhatt GM, Ellison FW, Mares DJ (1983). Inheritance studies in dormancy in three wheat crosses. In: Kruger JE, LaBerge DE (eds) Third International Symposium on Pre-Harvest Sprouting in Cereals. Westview Press: Boulder, Colorado. pp 274-278.

Buraas T, Skinnes H (1984). Genetic investigations on seed dormancy in barley. Hereditas 101: 235-244.

Cai HW, Morishima H (2000). Genomic regions affecting seed shattering and seed dormancy in rice. Theor Appl Genet 100: 840-846.

Chang TT, Tagumpay O (1973). Inheritance of grain dormancy in relation to growth duration in 10 rice crosses. SABRAO Newsl 5: 87-94.

Chang TT, Yen ST (1969). Inheritance of grain dormancy in four rice crosses. Bot Bul Acad Sin 10: 1-9.

Clerkx EJ, El-Lithy ME, Vierling E, Ruys GJ, Blankestijn-De Vries H, Groot SP et al (2004). Analysis of natural allelic variation of Arabidopsis seed germination and seed longevity traits between the accessions Landsberg erecta and Shakdara, using a new recombinant inbred line population. Plant Physiol 135: 432-443.

Dong Y, Tsozuki E, Kamiunten H, Terao H, Lin D, Matsuo M et al (2002). Identification of quantitative trait loci associated with pre-harvest sprouting resistance in rice (Oryza sativa L.). Field Crops Res 81: 133-139.

Flintham JE (2000). Different genetic components control coatimposed and embryo-imposed dormancy in wheat. Seed Sci Res 10: 43-50.

Gao W, Clancy JA, Han F, Prada D, Kleinhofs A, Ullrich SE (2003). Molecular dissection of a dormancy QTL region near the chromosome $7(5 \mathrm{H})$ L telomere in barley. Theor Appl Genet 107: 552-559.

Gfeller F, Svejda F (1960). Inheritance of post-harvest seed dormancy and kernel colour in spring wheat lines. Can J Plant Sic 40: 1-6.

Groos C, Gay G, Perretant MR, Gervais L, Bernard M, Dedryver $F$ et al (2002). Study of the relationship between pre-harvest sprouting and grain color by quantitative trait loci analysis in a white $\times$ red grain bread-wheat cross. Theor Appl Genet 104: 39-47.

$\mathrm{Gu}$ X-Y, Chen Z-X, Foley ME (2003). Inheritance of seed dormancy in weedy rice. Crop Sci 43: 835-843.

Gu X-Y, Kianian SF, Foley ME (2004). Multiple loci and epistases control genetic variation for seed dormancy in weedy rice (Oryza sativa). Genetics 166: 1503-1516.

Gu X-Y, Kianian SF, Foley ME (2005). Phenotypic selection for dormancy introduced a set of adaptive haplotypes from weedy into cultivated rice. Genetics 21 June [Epub ahead of print].

Han F, Ullrich SE, Clancy JA, Romagosa I (1999). Inheritance and fine mapping of a major barley seed dormancy QTL. Plant Sci 143: 113-118.

Johnson LPV (1935). The inheritance of delayed germination in hybrids of Avena fatua and A. sativa. Can J Res 13: 367-387.

Kato K, Nakamura W, Tabiki T, Miura H (2001). Detection of loci controlling seed dormancy on group 4 chromosomes of wheat and comparative mapping with rice and barley genomes. Theor Appl Genet 102: 980-985.

Koornneef M, Karssen CM (1994). Seed dormancy and germination. In: Koornneef M, Karssen CM (eds) Arabidopsis. Cold Springs Harbor Laboratory Press: Cold Springs. pp 313-334.

Kulwal PL, Singh R, Balyan HS, Gupta PK (2004). Genetic basis of pre-harvest sprouting tolerance using single-locus and two-locus QTL analyses in bread wheat. Funct Integr Genomics 4: 94-101.

Kearsey MJ, Pooni HS (1996). The Genetical Analysis of Quantitative Traits. Chapman \& Hall: London.

Leopold AC, Glenister R, Cohn MA (1988). Relationship between water content and afterripening in red rice. Plant Physiol 74: 659-662. 
Li CD, Tarr A, Lance RCM, Harasymow S, Uhlmann J, Westcot $S$ et al (2003). A major QTL controlling seed dormancy and pre-harvest sprouting/ $\alpha$-amylase in two-rowed barley (Hordeum vulgare L.). Aust J Agric Res 54: 1303-1313.

Lijavetzky D, Martinez MC, Carrari F, Hopp HE (2000). QTL analysis and mapping of pre-harvest sprouting resistance in sorghum. Euphytica 112: 125-135.

Lin SY, Sasaki T, Yano M (1998). Mapping quantitative trait loci controlling seed dormancy and heading date in rice. Theor Appl Genet 96: 997-1003.

Lincoln S, Daly M, Lander E (1992). Constructing Genetic Maps With MAPERMAKER/EXP 3.0 (3rd edn). Whitehead Institute: Cambridge, MA.

Mares DJ, Mrva K (2001). Mapping quantitative trait loci associated with variation in grain dormancy in Australian wheat. Aust J Agric Res 52: 1257-1265.

Miura K, Lin SY, Yano M, Nagamine T (2002). Mapping quantitative trait loci controlling seed longevity in rice (Oryza sativa L.). Theor Appl Genet 104: 981-986.

Nilsson-Ehle H (1914). Zur kenntnis der mit der keimungsphysiologie des weizens in zusammenhang stehenden inneren faktoren. Z Pflanzenzüchtung 2: 153-187.

Oberthur L, Blake TK, Dyer WE, Ullrich SE (1995). Genetic analysis of seed dormancy in barley (Hordeum vulgare L.). J Quant Trait Loci 1: 5.

Osa M, Kato K, Mori M, Shindo C, Torada A, Miura H (2003). Mapping QTLs for seed dormancy and the $V p 1$ homologue on chromosome 3A in wheat. Theor Appl Genet 106: 1491-1496.

Prada D, Ullrich SE, Molina-Cano JL, Cistue L, Clancy JA, Romagosa I (2004). Genetic control of dormancy in a
Triumph/Morex cross in barley. Theor Appl Genet 109: 62-70.

Roberts EH (1961). Dormancy in rice seed. I. The distribution of dormancy period. I Exp Bot 12: 319-329.

SAS Institute Inc. (1999). SAS/STAT User's Guide, Version 8, Cary, NC, USA.

Simpson GM (1990). Seed Dormancy in Grass. Cambridge University Press: Cambridge. pp 3-113.

Takahashi N (1962). Physiocogenetical studies on germination of rice seeds with special reference to its genetical factors (in Japanese, with English summary). Bull Inst Agric Res Tohoku Univ 14: 1-87.

Takeuchi Y, Lin SY, Sasaki T, Yano M (2003). Fine linkage mapping enables dissection of closely linked quantitative trait loci for seed dormancy and heading in rice. Theor Appl Genet 107: 1174-1180.

Thomson MJ, Tai TH, McClung AM, Lai XH, Hinga ME, Lobos $\mathrm{KB}$ et al (2003). Mapping quantitative trait loci for yield, yield components and morphological traits in an advanced backcross population between Oryza rufipogon and the Oryza sativa cultivar Jefferson. Theor Appl Genet 107: 479-493.

Veasey EA, Karasawa MG, Santos PP, Rosa MS, Mamani E, Oliveira GC (2004). Variation in the loss of seed dormancy during after-ripening of wild and cultivated rice species. Ann Bot (Lond) 94: 875-882.

Van der Schaar W, Alonso-Blanco WC, Leon-Kloosterziel KM, Jansen RC, Van Ooijen JW, Koornneef M (1997). QTL analysis of seed dormancy in Arabidopsis using recombinant inbred lines and MQM mapping. Heredity 79: 190-200.

Wan J, Nakazaki T, Kawaura K, Ikehashi H (1997). Identification of marker loci for seed dormancy in rice (Oryza sativa L.). Crop Sci 37: 1759. 